\title{
BMJ Open Cohort profile: the Men and Parenting Pathways (MAPP) Study: a longitudinal Australian cohort study of men's mental health and well-being at the normative age for first-time fatherhood
}

\author{
Jacqui A Macdonald (D) , ,2,3 Lauren M Francis (D) , ${ }^{1}$ Helen Skouteris (D) ,,5 \\ George J Youssef (D) ,1,2 Liam G Graeme (D) , ${ }^{1}$ Joanne Williams (D) ,6,7 \\ Richard J Fletcher (D) , ${ }^{8}$ Tess Knight (D) , 9 Jeannette Milgrom (D) , ${ }^{10,11}$ \\ Laura Di Manno (D) , ${ }^{1}$ Craig A Olsson (D) , ${ }^{1,2,3}$ Christopher J Greenwood (D) ${ }^{1,2}$
}

To cite: Macdonald JA, Francis LM, Skouteris $\mathrm{H}$, et al. Cohort profile: the Men and Parenting Pathways (MAPP) Study: a longitudinal Australian cohort study of men's mental health and well-being at the normative age for firsttime fatherhood. BMJ Open 2021;11:e047909. doi:10.1136/ bmjopen-2020-047909

- Prepublication history for this paper is available online. To view these files, please visit the journal online (http://dx.doi org/10.1136/bmjopen-2020047909).

Received 11 December 2020 Accepted 05 July 2021

D) Check for updates

(c) Author(s) (or their employer(s)) 2021. Re-use permitted under CC BY-NC. No commercial re-use. See rights and permissions. Published by BMJ.

For numbered affiliations see end of article.

\section{Correspondence to} Dr Jacqui A Macdonald; jacqui.macdonald@deakin. edu.au

\section{ABSTRACT}

Purpose The Men and Parenting Pathways (MAPP) Study is a prospective investigation of men's mental health and well-being across the normative age for transitioning to fatherhood. This includes trajectories and outcomes for men who do and do not become fathers across five annual waves of the study.

Participants Australian resident, English-speaking men aged 28-32 years at baseline were eligible. Recruitment was over a 2-year period (2015-2017) via social and traditional media and through engagement with study partners. Eight hundred and eighteen eligible men consented to participate. Of these, 664 men completed the first online survey of whom 608 consented to ongoing participation. Of the ongoing sample, $83 \%$ have participated in at least two of the first three annual online surveys.

Findings to date Three waves of data collection are complete. The first longitudinal analysis of MAPP data, published in 2020, identified five profiles that characterise men's patterns of depressive symptom severity and presentations of anger. Profiles indicating pronounced anger and depressive symptoms were associated with fathers' lack of perceived social support, and problems with coparenting and bonding with infants. In a second study, MAPP data were combined with three other Australian cohorts in a meta-analysis of associations between fathers' self-reported sleep problems up to 3 years postpartum and symptoms of depression, anxiety and stress. Adjusted meta-analytic associations between paternal sleep and mental health risk ranged from 0.25 to 0.37 .

Future plans MAPP is an ongoing cohort study. Waves 4 and 5 data will be ready for analyses at the end of 2021. Future investigations will include crossed-lagged and trajectory analyses that assess inter-relatedness and changing social networks, mental health, work and family life. A nested study of COVID-19 pandemic-related mental health and coping will add two further waves of data collection in a subsample of MAPP participants.
Strengths and limitations of this study

- The Men and Parenting Pathways (MAPP) Study addresses a well-documented gap in longitudinal research that tracks men before, during and post the transition to fatherhood.

- MAPP includes repeated annual measurement of contextual, individual and relational factors that may be associated with risk for mental health problems and maladaptive behaviours in the early parenting years.

- Only self-report assessments are included and may be subjected to associated reporting biases.

- MAPP has had strong participation rates with $83 \%$ of men completing at least two of the first three waves.

- The MAPP cohort has higher rates of men in paid employment and lower rates of men born outside of Australia than men of the same age in the Australian population.

\section{INTRODUCTION}

Many men struggle to psychologically adjust to fatherhood with reverberating effects on family functioning and offspring development. ${ }^{1-3}$ Across the perinatal period, at least 1 in 10 fathers are estimated to experience clinically relevant symptoms of generalised psychological distress, depression, anxiety and/or stress. ${ }^{4-8}$ Paternal mental health problems increase the risk of maternal depression, child social and behavioural problems and relationship conflict. ${ }^{3}$ 9-12 Conversely, good psychological adjustment enhances a father's capacity to positively contribute to the psychosocial development of his offspring. ${ }^{13-15}$ Supporting men's adjustment to fatherhood is, therefore, a critical component of reducing 
risk and promoting positive outcomes in emerging family environments.

Factors relevant to suboptimal or maladaptive transitions to parenthood often exist prior to infant conception. This realisation has led to the emergence of preconception care plans for men, an example of which is the 'reproductive life plan' developed by the US Centers for Disease Control. ${ }^{16}$ The targets of preconception care are largely health-based behaviours related to obesity, smoking and alcohol use, but these programmes also recognise the importance of psychosocial risks such as anxiety, depressive symptoms, aggressive behaviours and deficient coping skills that carry over to the postnatal period. ${ }^{17}$ This acknowledges potential for men's preconception functioning to be of considerable consequence to their future selves, partners and offspring. An aim of preconception care is to improve men's capacity to be good fathers and, therefore, avert intergenerational risk that can arise out of paternal psychosocial problems. ${ }^{17}$ However, a lack of consensus among clinicians about what behaviours should be targeted, and how to target them, remains a considerable barrier to developing preconception and perinatal care programmes for men. ${ }^{17-19}$

Perinatally, healthcare providers and fathers also encounter multiple obstacles in respectively offering or gaining appropriate access to paternal support. These include widespread failure to identify men's psychological problems, ${ }^{20}$ maternal-infant focused family support services that are not father-inclusive ${ }^{18}$ and a scarcity of interventions for men when need is identified. ${ }^{21}$ At the normative age for becoming a father, overcoming these barriers is critical, particularly in the context of an alarming rate of suicide among men aged 29-44 years, which is three to four times that of women. ${ }^{22} 23$

A key factor undermining the development and implementation of effective preconception and perinatal programmes for men is limited evidence. There are few well-designed cohort studies that have specifically explored the immediate developmental precursors to fatherhood. Much of the research on men in the transition to parenthood has been limited to antenatal and postnatal data collection with only retrospective recall of behaviours before pregnancy, if any assessment at all. ${ }^{24} 25$ Studies encompassing the transition from preconception to parenthood that do have longitudinal designs are often focused on broader epidemiological explorations, predominantly child development and family health (eg, Avon Longitudinal Study of Parents and Children) ${ }^{26}$ or broad determinants of male health across a wider age range (eg, Ten to Men). ${ }^{27}$ Longitudinal studies with a primary focus on the transition to fatherhood typically recruit in gestational or postpartum periods and so have been unable to prospectively address questions about preconception antecedents of psychological well-being during early fatherhood. ${ }^{28}$ Not surprisingly, most studies that investigate new fatherhood only include fathers and so comparisons have not been possible with childless men at the same developmental stage. These studies are unable to address the question of whether mental health risks are a feature of the parenthood role and its accompanying stressors or the cohort age and life stage.

In 2017, an audit of cohort studies in the UK reported that the amount of data collected on fathers was 'meagre'. The report found that when data on fathers were collected, the survey respondents were often their partners or children. ${ }^{29}$ By way of example, in a 2016 systematic review of fathers' representation in observational research on parenting and child obesity, just $1 \%$ of the 667 included studies sampled only fathers compared with $36 \%$ that sampled only mothers. Across all studies, fathers represented only $17 \%$ of parent participants and results on them were rarely reported separately. ${ }^{30}$

Prior to now, there has been a lack of theoretically driven prospective research that includes men recruited in the preconception period. As such, there is a scarcity of research specifically designed to capture men's transition to parenthood with adequate assessment of factors including role identity, social support and quality of relationships. These are among accepted mechanisms in women's positive transition to motherhood, ${ }^{31}$ but considerably less is known about their influence on men's transition to fatherhood. Understanding this transition is especially important in the context of a reshaping of the traditional fatherhood role.$^{32}$ Compared with earlier generations, greater expectations now exist for father involvement with children and for expressions of emotionality and bonding, yet many men enter fatherhood without clear intergenerational models. ${ }^{33}$ Lack of role clarity adds stress to an already challenging transition. ${ }^{34}$

The Men and Parenting Pathways (MAPP) Study presents an opportunity to identify risk and protective factors at the normative age for transition to fatherhood that mark capacity in men to become successful caregivers. While fatherhood is a normative developmental transition for men that usually occurs in the years that follow emerging adulthood, not all men become fathers at this time or ever. ${ }^{35}$ Men who do not transition to fatherhood during this period nevertheless experience substantial changes to social networks as their peers become parents. Some men elect to remain childfree. ${ }^{36}$ Others are without children for other reasons including biological obstacles. ${ }^{37}$ The psychosocial well-being and mental health risks of these men are not well understood and are also investigated within the MAPP Study.

\section{COHORT DESCRIPTION}

\section{Study design}

MAPP is a five-wave longitudinal study with data collection conducted annually via online web surveys. The study was restricted to a 5-year period to focus on the normative transitional age for fatherhood and to present participants on consent with a finite understanding of their commitment to the study. Key measures of mental health and psychosocial functioning are repeated at 
each wave to allow for examination of relationships both cross-sectionally and over time. Longitudinal assessments allow for analyses that take into account changing lifestyle factors at the peak age for entering fatherhood that may influence or be influenced by mental health. These are measured across domains of family, romantic and peer relationships, workplace stress, roles and identity and behaviours including alcohol and substance use. The multiple domains also allow for person-centred profile analyses that can identify groups of men with varying degrees of vulnerability to poorer outcomes by virtue of their patterns of risk and protective factors. ${ }^{38}$

\section{MAPP recruitment and inclusion}

The target population was Australian resident, Englishspeaking men, with or without children, aged 28-32 years. The age range represents the 5 years preceding the median age in Australia for becoming a first-time father in 2015 (33 years). ${ }^{39}$ Recruitment occurred over a 2-year period beginning February 2015. Participants learnt about the study predominantly via Facebook paid posts $(75 \%)$. Participants were offered entry into monthly draws for prizes worth no more than $\$ A 100$ on completion of each annual survey. Example prizes included tickets to sporting matches and retail vouchers.

Sample characteristics were monitored during the recruitment period, which allowed for posts to be targeted via Facebook selection algorithms to underrepresented population sectors, locales or SES groups. Recruitment followed social media strategies validated by the Australian Longitudinal Study of Women's Health, which were reported to be effective methods resulting in that study producing a nationally representative sample within a restricted age range. ${ }^{40}$

The remaining sample was recruited via workplace and community organisations and clubs $(10 \%)$, a partnership with a national retailer of camping products $(7 \%)$ and 'other' methods including promotion of the study in newspapers and on radio (8\%). All study promotion materials included a link to the Plain Language Statement and online consent form on the REDCap secure data capture web platform ${ }^{41}$ hosted at the Murdoch Children's Research Institute. Eligible participants were asked on the same online form to consent separately for participation in the first survey and the ongoing longitudinal study.

\section{Participation}

As outlined in figure 1 , of those who completed the consent form, $85 \%$ were eligible for inclusion and, of those, $81 \%$ participated in the wave 1 survey $(n=664)$. Of the wave 1 sample, $92 \%$ agreed via the original consent form to be contacted for ongoing participation in five annual waves of data collection. This group $(n=608)$ is known as the MAPP Study ongoing sample of whom $83 \%$ have participated in at least two of the first three data collection waves. By the completion of wave 3 , no participant had withdrawn from the study.

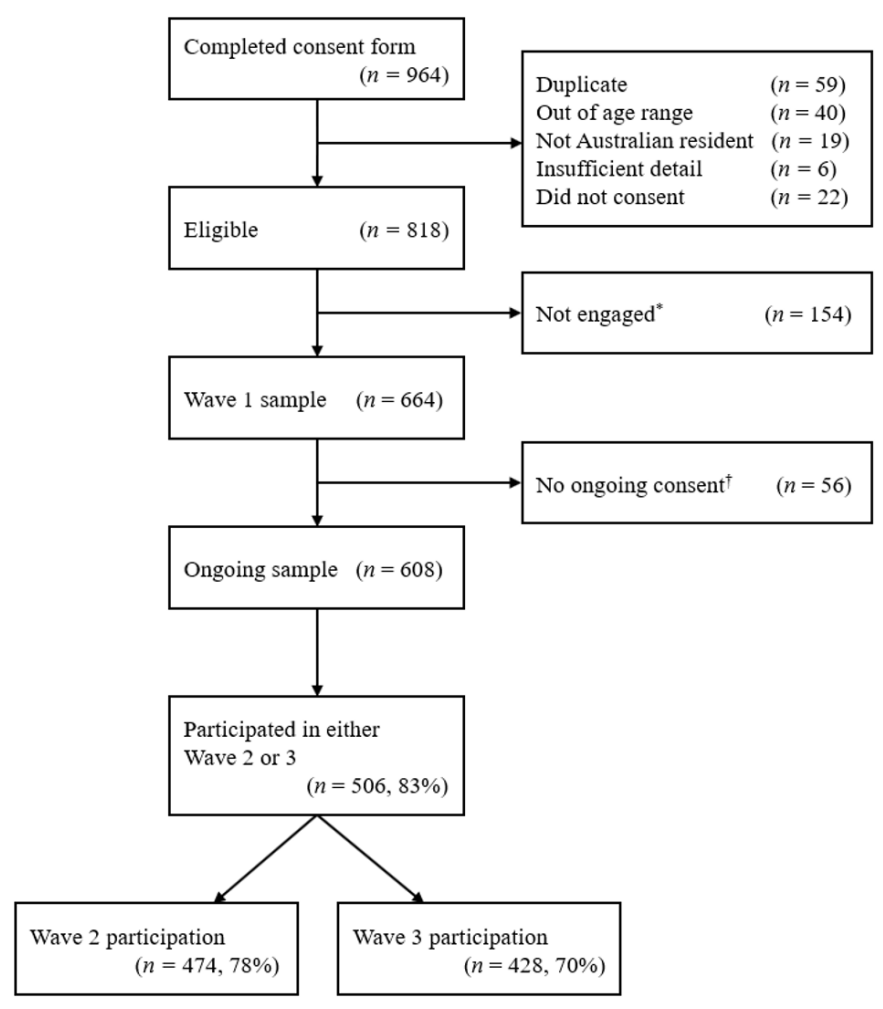

Figure 1 Men and Parenting Pathways Study flow diagram of inclusion and participation. *Consented and eligible but did not complete wave 1 or completed insufficient wave 1 items to warrant ongoing inclusion. †Provided consent to wave 1 but not to ongoing participation.

\section{Participant engagement strategies and procedures}

On the anniversary of their previous survey's completion, participants are sent an automated email invitation with a unique link to their next annual survey. If not completed, an automated reminder is emailed 1 week later. Each year, participants are informed that on survey completion, they will be entered for 12 months into a monthly prize draw for a $\$$ A100 store voucher. At each wave, approximately $31 \%$ complete their surveys without further follow-up. For the remainder of the cohort, research assistants and trained student interns attempt to make contact via a participant's preferred method/s, including telephone call, Facebook message or text message. Surveys are closed 3 months after the first email invitation. If a participant does not take part in a wave, they are sent an automated invitation to the next wave on the next anniversary of their prior participation. MAPP Study participants are also engaged via an annual newsletter, social media posts and updates to the study website.

\section{Sample size}

A target sample size of approximately 600 men was deemed suitable to address the study aims and to be manageable given resources required for longitudinal follow-up and retention strategies of a typically difficult to recruit and retain population. ${ }^{30} 42$ Power is demonstrated for a common analytical design of the project, which is the estimation of an exposure-outcome relationship of 
interest (after covariate adjustment) using linear regression. Using Monte Carlo simulations (10000 draws) in Mplus V.8, ${ }^{43}$ our achieved sample size of 608 provides $95.6 \%$ power to detect a true effect of interest (eg, associations between avoidant coping strategies and subsequent depressive symptoms) of even small magnitude $(\beta=0.14$, representing just $\sim 2 \%$ extra variance accounted for in the outcome above a base level of $10 \%$ by other variables in the model; $\alpha=0.05$, two tailed). Even with $20 \%$ attrition $(\mathrm{n}=486)$, power for the same analytical model is $90.6 \%$. Latent class analysis (LCA) models will be our approach to identifying subgroups of participants with different profiles of risk and protective factors in the larger data set. Monte Carlo simulation studies show that our sample size of 608 will be suitable to estimate a range of LCA models. ${ }^{3844}$ Additionally, at the conclusion of wave 3 , and in subsequent data collection up to the time of writing, identified first-time fathers, post wave 1 , now exceed 100 , which meets minimum cell sample size recommendations. ${ }^{45}$ Consequently, our planned analytical methods are well powered.

\section{Cohort characteristics}

All six Australian states and two territories are represented within the MAPP cohort. Participant mean age at wave 1 of the ongoing sample $(\mathrm{n}=608)$ was 30.4 years $(\mathrm{SD}=1.4)$. Compared with the Australian population, the MAPP ongoing sample shares a similar geographic spread across areas of socio-economic advantage and disadvantage (Socio-Economic Indexes For Areas $[\mathrm{SEIFA}]^{46}$; $\mathrm{t}_{607}=1.47, \mathrm{p}=0.14$, Cohen's $\left.\mathrm{d}=0.05\right)$. Compared with rates within Australian men aged 30-34years, ${ }^{47} 48$ MAPP has a similar proportion of participants with post-high school education ( $\mathrm{z}=1.60, \mathrm{p}=0.11$, Cohen's $\mathrm{h}=0.07)$ and a higher proportion of men in paid employment $(\mathrm{z}=3.30, \mathrm{p}=0.001$, Cohen's $h=0.15$ ). The proportion of MAPP men born outside of Australia is lower than the proportion of men 30-34 years born overseas who responded to the 2016 Australian census ${ }^{49}$ ( $\mathrm{z}=-13.11, \mathrm{p}<0.001$, Cohen's $\mathrm{h}=0.618$ ); however, it should be noted that MAPP eligibility required participants to be Australian residents, whereas the census records all people in Australia on the census date including non-residents and temporary visitors. The proportion of participants of Aboriginal or Torres Strait Islander background is equivalent to men $30-34$ years in the Australian population ${ }^{50}(\mathrm{z}=-1.22$, $\mathrm{p}=0.22$, Cohen's $\mathrm{h}=0.05$ ). The proportion of men who identify as heterosexual is slightly lower than recorded Australian rates ${ }^{51}(\mathrm{z}=-3.76, \mathrm{p}<0.001$, Cohen's $\mathrm{h}=0.14)$. Compared with the proportion of fathers in the Australian Longitudinal Study on Male Health aged 28-32 years, ${ }^{52}$ MAPP had fewer men at wave 1 who were already fathers $(\mathrm{z}=-4.29, \mathrm{p}<0.001$, Cohen's $\mathrm{h}=0.21)$.

Cohort sample characteristics are presented in table 1. On key demographic characteristics assessed at baseline, there were no differences identified between the MAPP wave 1 and MAPP ongoing samples and no differences between the ongoing sample and those who responded in waves 2 and/or 3 .

At wave 1, there were 241 fathers of 421 children ( $90.5 \%$ biological; $9 \%$ step; $0.5 \%$ other). Of the nonfathers $(n=367), 67$ were identified as becoming a new father in wave $2(n=35)$ or $3 \quad(n=32)$. Overall, there were 91 identified new births in wave 2 and 65 identified new births in wave 3 . Average age at first biological child was 27.4 years $(\mathrm{SD}=3.9)$. In data collections following wave 3 , we have further identified 44 additional new parents, resulting in over 100 identified fathers who have transitioned to parenthood within the course of the study. At wave 1 , of participants without biological children, $6 \%$ reported being aware of a biological reason that they or their partner could not have children in the future. The total number of new fathers will not be known until completion of wave 5 data collection. At baseline, $79.8 \%$ of men were in a relationship. Of the 491 children, $88.4 \%$ lived with the participant father, $10.1 \%$ were not living with the participant fathers and $1.5 \%$ were reported to have other living arrangements.

Depression, anxiety and stress in the MAPP Study are assessed at each wave with the 21-item Depression, Anxiety, Stress Scales (DASS-21), ${ }^{53}$ which have validated cut points designating normal, mild, moderate, severe and extremely severe levels of mental health symptoms. ${ }^{54}$ Figure 2 indicates the proportion of participants who endorsed depressive, anxiety and stress symptoms at each severity level. In MAPP, $47 \%$ of the cohort reported some level of depressive symptomatology higher than 'normal', indicating symptoms that warrant further investigation. Approximately, one-third of the cohort reported at least mild levels of anxiety and 39\% reported mild to extremely severe stress.

Normative data for the DASS scales only differentiates two age groups, 18-24year olds and 25-90year olds. ${ }^{55}$ It is, therefore, not possible to draw definitive conclusions about MAPP cohort rates of mental health risk by making comparisons with scale norms. It is also difficult to assess rates against Australia's National Survey of Mental Health and Wellbeing, which was last conducted in $2007 .^{56}$ In that survey, using the World Mental Health Survey, Composite International Diagnostic Interview, ${ }^{57} 22.8 \%$ of men aged $25-34$ years were found to have 'any mental disorder' in the past 12 months; $11.5 \%$ had anxiety disorders and $7 \%$ had affective disorders. However, true prevalence is likely to be higher. The national survey response rate was only $60 \%$ and an evaluation of nonresponse bias found evidence of underestimation in the prevalence of men's mental health conditions. ${ }^{58}$

Some more recent prevalence data on depressive symptomatology, collected in 2013 to 2014, are available from the Australian Longitudinal Study on Male Health, Ten to Men. In that study, $39.1 \%$ of participants aged 25-34 years $(n=3058)$, reported mild to severe symptoms of depression as assessed with the brief Patient Health Questionnaire9. ${ }^{59}$ In $13.1 \%$ of the sample in that age bracket, symptoms were classified as moderate to severe. ${ }^{60}$ The Ten to Men response rate from identified eligible males was $35 \%,{ }^{61}$ and while weightings are applied to data to 


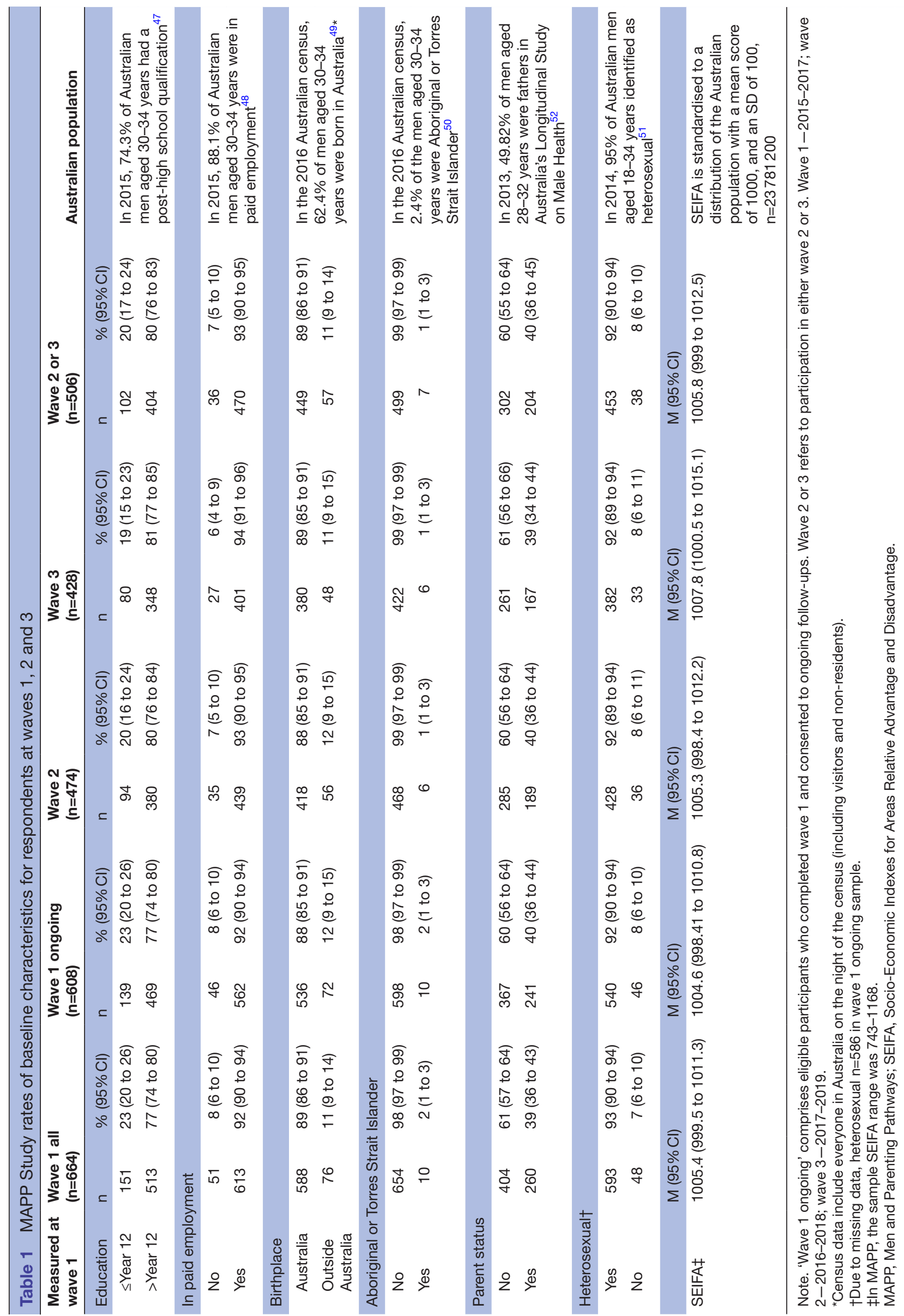



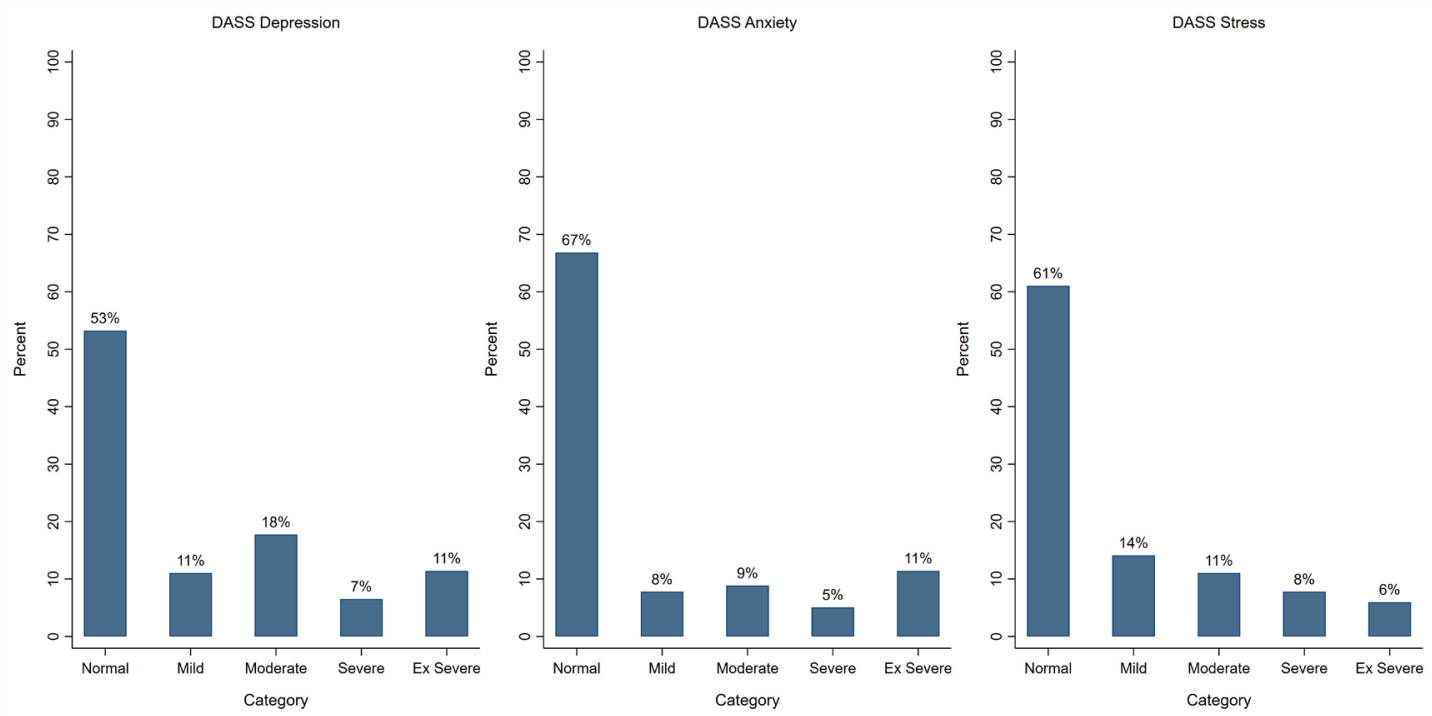

Figure 2 Proportions of participants at wave 1 in each DASS-21 severity category for symptoms of depression, anxiety and stress (normal, mild, moderate, severe and extremely severe).

align to representative demographics, it is not known if non-response introduced biases related to prevalence of mental health symptoms. In the ongoing MAPP sample at wave $1,18 \%$ of men reported depressive symptoms at severe or very severe levels. Proportions of severe to very severe anxiety or stress in MAPP were $16 \%$ and $14 \%$, respectively. Mental health symptom rates in MAPP appear to be more similar to those reported by a Swedish study of 447 fathers in which $27 \%$ were at risk of depression as indicated by the Beck Depression Inventory II. $^{62}$ There is some evidence from past research to suggest a greater willingness among men with mental health concerns to engage in research when recruitment is conducted online, ${ }^{63}$ which was a feature of both the MAPP and Swedish cohorts.

\section{Instrumentation}

Measures were selected to capture participant personality and emotional functioning alongside indicators of functioning within intersecting levels of family, social and work life. Key indicators of these are repeated across the five waves to track change over time and across major life transitions, particularly fatherhood. Scale selection took into account validation in male samples and brevity to reduce respondent burden. Family of origin information was collected only in wave 1 and measures of stable traits are also assessed at only one timepoint. We have sought to maximise continuity of measurement, pre and post entering fatherhood and allow for comparisons between fathers and non-fathers. This required, in some instances, the selection of broadly inclusive instruments rather than specific parenting measures. An example is the use of the Reflective Functioning Questionnaire ${ }^{64}$ that can be administered to all participants, rather than the Parental Reflective Functioning Questionnaire that would be applicable only to men who were fathers given items that specifically reference the respondent's child. ${ }^{65}$ Parenting measures are administered only to fathers and are specifically targeted at the developmentally relevant of age of the participants' child. An example is the Paternal Postpartum Attachment Scale ${ }^{66}$ which is only assessed in men with infants aged 18 months or younger. Table 2 provides an overview of the constructs measured at each wave.

\section{COVID-19 pandemic assessments}

Following completion of wave 3 data collection, Australia's first community transmission case of SARS-CoV-2 was detected in March 2020. By the end of that month, the Australian federal, state and territory governments announced a national response that included the shutdown of non-essential industries and the directive to 'stayat-home' with few exceptions. This led to the apparent suppression of the virus across the country. ${ }^{67}$ However, in June, there was sharp escalation of cases in the state of Victoria, which is where the MAPP Study is based and where $43 \%$ of the ongoing sample reside. The Victorian State Government responded by enforcing one of the world's most extended and strictest lockdowns at the time $^{68}$ All non-food retail and hospitality workplaces closed, and construction and other industries scaled back to minimal workforces. Childcare remained open only for children of essential workers and older children were schooled remotely. A curfew from $8 \mathrm{pm}$ to $5 \mathrm{am}$ was enforced along with a directive to stay within $5 \mathrm{~km}$ of home. By the end of October 2020, restrictions were being progressively lifted ${ }^{68}$ In March 2020, we recruited a subsample of MAPP participants $(n=286)$ to assess coping and mental health during this period. Additional questions were asked about exposure of self or family to COVID-19 infections and about pandemic-related life changes. Data from the nested MAPP COVID-19 pandemic study will be critical for later understanding MAPP Study participants' psychosocial functioning in waves 4 and 5 . 
Table 2 MAPP Study domains and constructs measured at each annual assessment

\begin{tabular}{|c|c|c|c|c|c|}
\hline Measures & Wave 1 & Wave 2 & Wave 3 & Wave 4 & Wave 5 \\
\hline \multicolumn{6}{|l|}{ Demographics } \\
\hline Date of birth & $\checkmark$ & $\checkmark$ & $\checkmark$ & $\checkmark$ & $\checkmark$ \\
\hline Gender & $\checkmark$ & - & - & - & - \\
\hline Ethnicity & $\checkmark$ & - & - & - & - \\
\hline Education & $\checkmark$ & $\checkmark$ & $\checkmark$ & $\checkmark$ & $\checkmark$ \\
\hline Sexual orientation & $\checkmark$ & $\checkmark$ & $\checkmark$ & $\checkmark$ & $\checkmark$ \\
\hline Living arrangements $^{76}$ & $\checkmark$ & $\checkmark$ & $\checkmark$ & $\checkmark$ & $\checkmark$ \\
\hline Income & $\checkmark$ & $\checkmark$ & $\checkmark$ & $\checkmark$ & $\checkmark$ \\
\hline Birthplace & $\checkmark$ & - & - & - & - \\
\hline Relationship status & $\checkmark$ & $\checkmark$ & $\checkmark$ & $\checkmark$ & $\checkmark$ \\
\hline Relative advantage/disadvantage ${ }^{46}$ & $\checkmark$ & - & - & - & - \\
\hline
\end{tabular}

\section{Mental health}

\begin{tabular}{|c|c|c|c|c|c|}
\hline Depression $^{53}$ & $\checkmark$ & $\checkmark$ & $\checkmark$ & $\checkmark$ & $\checkmark$ \\
\hline Anxiety $^{53}$ & $\checkmark$ & $\checkmark$ & $\checkmark$ & $\checkmark$ & $\checkmark$ \\
\hline Stress $^{53}$ & $\checkmark$ & $\checkmark$ & $\checkmark$ & $\checkmark$ & $\checkmark$ \\
\hline Irritability $^{77}$ & $\checkmark$ & $\checkmark$ & $\checkmark$ & $\checkmark$ & $\checkmark$ \\
\hline State anger ${ }^{78}$ & $\checkmark$ & $\checkmark$ & $\checkmark$ & $\checkmark$ & $\checkmark$ \\
\hline Shame $^{79}$ & - & - & - & $\checkmark$ & $\checkmark$ \\
\hline \multicolumn{6}{|l|}{ Vell-being } \\
\hline Environmental mastery ${ }^{80}$ & $\checkmark$ & $\checkmark$ & $\checkmark$ & $\checkmark$ & $\checkmark$ \\
\hline Purpose in life $e^{80}$ & $\checkmark$ & $\checkmark$ & $\checkmark$ & $\checkmark$ & $\checkmark$ \\
\hline Reflective functioning ${ }^{64}$ & - & - & $\checkmark$ & $\checkmark$ & $\checkmark$ \\
\hline Coping $^{81}$ & - & - & $\checkmark$ & $\checkmark$ & $\checkmark$ \\
\hline Understood/misunderstood ${ }^{82}$ & - & - & $\checkmark$ & $\checkmark$ & $\checkmark$ \\
\hline Risk-taking $^{83}$ & - & - & - & $\checkmark$ & $\checkmark$ \\
\hline
\end{tabular}

\section{Parenting}

$\begin{array}{lc}\text { Father-infant bonding }^{66} & \checkmark \\ \text { Paternal stress }^{84} & \checkmark \\ \text { Paternal involvement in childcare }^{85} & \checkmark \\ \text { Coparenting relationships }^{86} & \checkmark \\ \text { Parental decision making } & - \\ \text { Future parenting expectations } & \checkmark \\ \text { Desire to have children } & \\ \text { Parenting like own parent } & \checkmark\end{array}$

2
4
4
4
4
2
2
2
2

\begin{tabular}{|c|c|c|}
\hline$\checkmark$ & $\checkmark$ & $\checkmark$ \\
\hline$\checkmark$ & $\checkmark$ & $\checkmark$ \\
\hline$\checkmark$ & $\checkmark$ & $\checkmark$ \\
\hline$\checkmark$ & $\checkmark$ & $\checkmark$ \\
\hline$\checkmark$ & $\checkmark$ & $\checkmark$ \\
\hline$\checkmark$ & $\checkmark$ & $\checkmark$ \\
\hline$\checkmark$ & $\checkmark$ & $\checkmark$ \\
\hline 1 & $\checkmark$ & $\checkmark$ \\
\hline
\end{tabular}

\section{Family of origin}

Parent-child bonding (mother) $)^{88}$

Parent-child bonding (father) ${ }^{88}$

Parent separation/death

\section{Social relationships}

Social engagement

Social support ${ }^{89}$

Intimate relationship self and partner ${ }^{90}$

Dyadic adjustment ${ }^{91}$

Relationship duration

2
2
2

-
-
-

-
-
-

-
-
-

\begin{tabular}{|c|c|c|c|c|}
\hline$\checkmark$ & $\checkmark$ & $\checkmark$ & $\checkmark$ & $\checkmark$ \\
\hline$\checkmark$ & $\checkmark$ & $\checkmark$ & $\checkmark$ & $\checkmark$ \\
\hline$\checkmark$ & $\checkmark$ & $\checkmark$ & $\checkmark$ & $\checkmark$ \\
\hline$\checkmark$ & $\checkmark$ & $\checkmark$ & $\checkmark$ & $\checkmark$ \\
\hline$\checkmark$ & $\checkmark$ & $\checkmark$ & $\checkmark$ & $\checkmark$ \\
\hline
\end{tabular}


Table 2 Continued

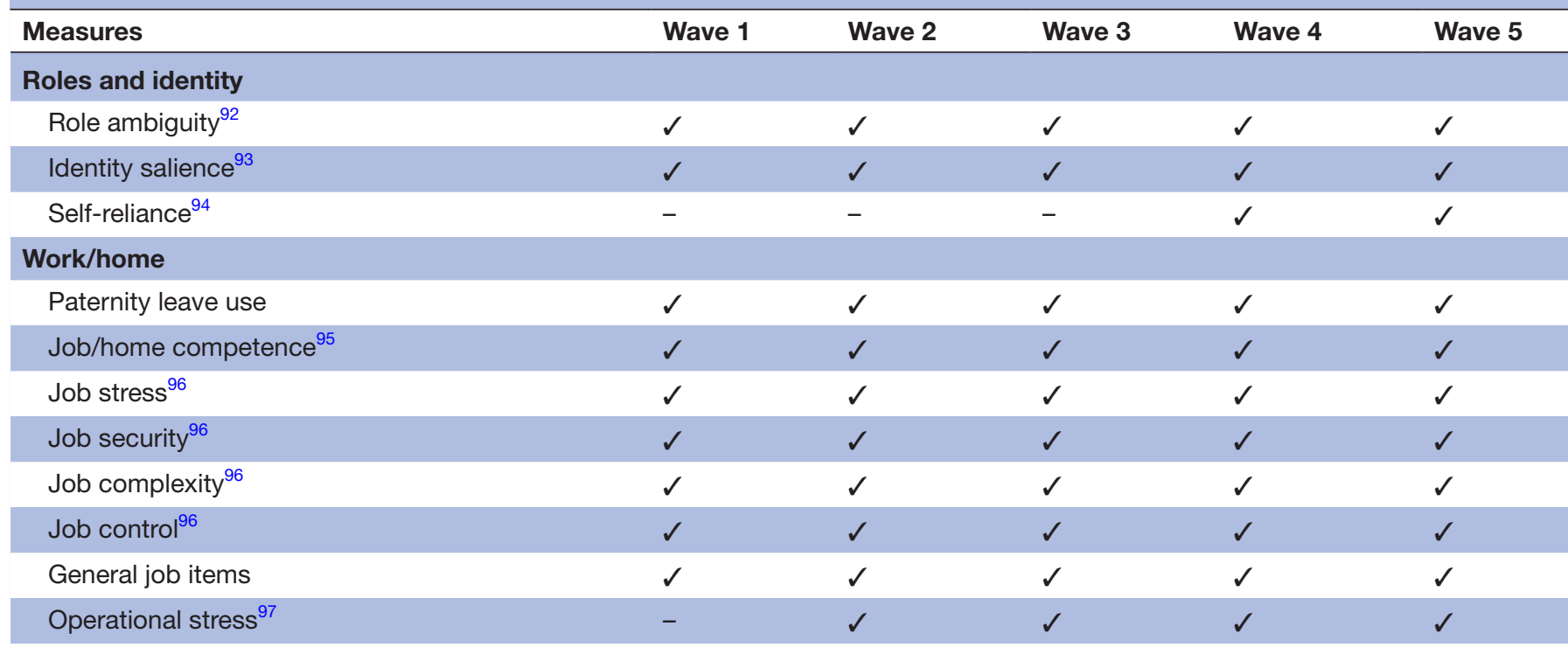

Traits

$\begin{array}{lllll}\text { Trait anger }^{78} & \checkmark & - & - & - \\ \text { Six factor model of personality }^{98} & - & \checkmark & - & - \\ \text { Socially prescribed perfectionism }^{99} & - & - & \checkmark & -\end{array}$

Overall health and events

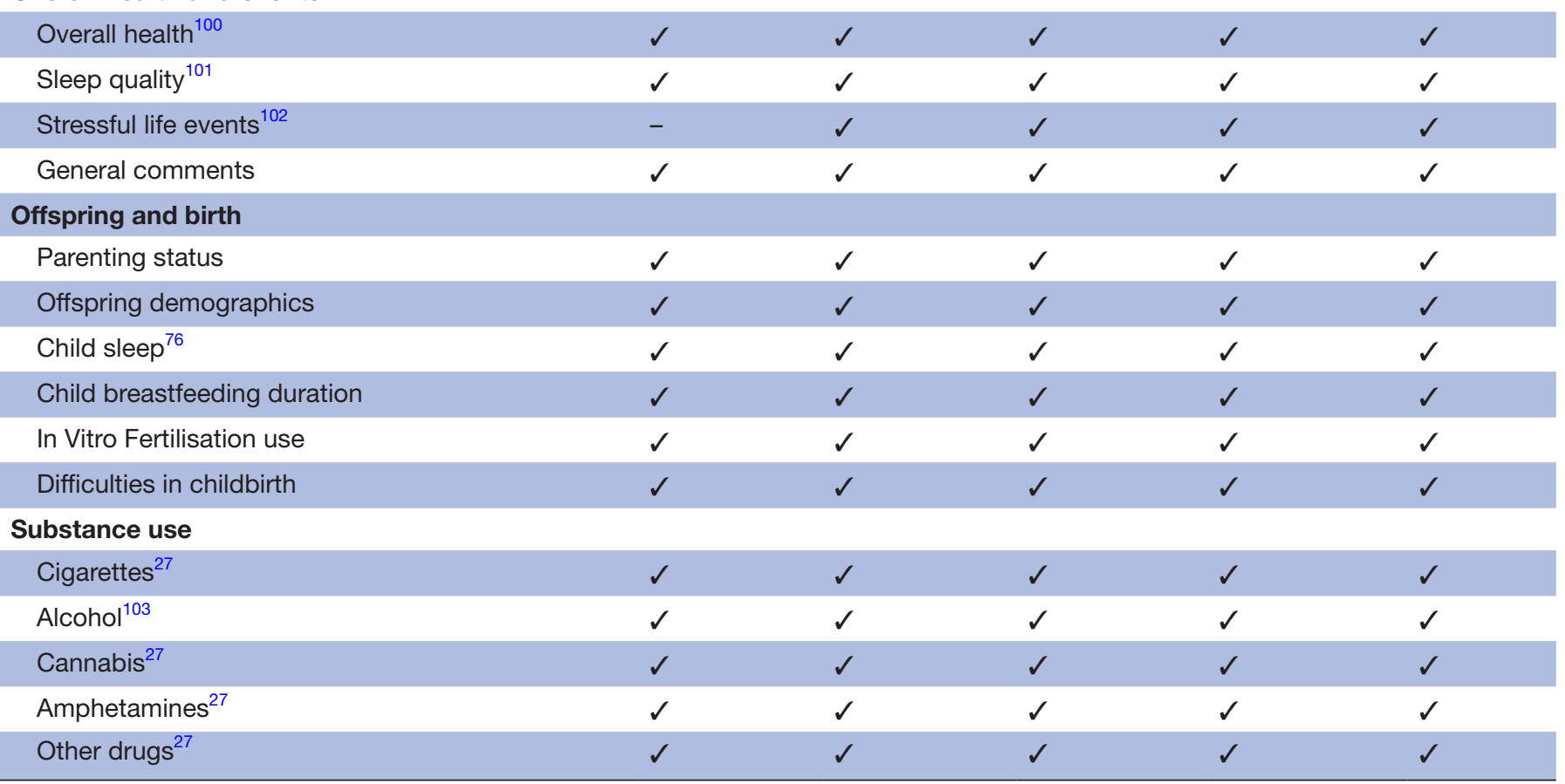

Note. $\checkmark$ indicates the construct was assessed at that wave. Data are collected annually with an invitation and survey link sent on the anniversary of completion of the last wave completed. Participants are given 3 months from the date of the wave invitation to complete the survey. Because of staggered recruitment, the data collection period extends from February 2015 to December 2021.

MAPP, Men and Parenting Pathways.

\section{Findings to date}

The first longitudinal analysis using MAPP data from waves 1 to 3 was published in $2020 .{ }^{69}$ We reported on five distinct class profiles of MAPP men in the ongoing sample at wave 1 that characterised their patterns of depressive symptom severity and presentations of state anger (feeling angry, feeling verbally angry or feeling physically angry). Four of the classes demonstrated symptom patterns that indicated psychological risk. The context for the study was a growing body of literature that indicates men are inclined to express depression through anger. Our aim was to consider risks that might present for the early 
family environment when fathers have coexisting depression and anger symptoms.

When we examined proportions of men with and without children within each class, we found that compared with men in our reference group class $(31 \%$ fathers) who had minimal evidence of depressive or anger symptomatology, there was a greater proportion of fathers compared with non-fathers in the mild symptom class (48\% fathers; OR=2.05, 95\% CI (1.37 to 3.08)) and in the most severe symptom class $(49 \%$ fathers; $\mathrm{OR}=2.12$, 95\% CI (1.05 to 4.25)). Among fathers who had infants aged 18 months or younger, compared with the reference class, we found that those with higher risk profiles had poorer relational outcomes including lower levels of perceived social support, greater coparenting problems and poorer father-infant bonds.

In a second study, data were combined from the MAPP Study and three other Australian cohorts in a metaanalysis of associations between fathers' self-reported sleep problems up to 3 years postpartum and symptoms of depression, anxiety and stress. After adjusting for father age, child age, household income, education level, first or later child and marital status, meta-analytic correlations between paternal sleep problems and symptoms of mental health problems ranged from $r=0.25$ to 0.37 . The associations were consistent across cohorts despite variability in measurement of both sleep and mental health. ${ }^{70}$

\section{Strengths and limitations}

To our knowledge, MAPP represents a unique study with recruitment of men approaching the peak age for entering fatherhood in order to specifically understand preconception risks and protective factors associated with a normatively timed transition to fatherhood. Despite calls for greater preconception engagement with prospective fathers, psychological and social factors that prepare men for fatherhood are vastly understudied compared with the equivalent in women. ${ }^{17}$ We deliberately narrowed eligibility to an age band approaching the peak age for fatherhood in order for us to understand the risks and protective factors that are relevant to a normative, 'on-time' transition to fatherhood. In this way, public health initiatives that this research can inform should be relevant to the largest proportion of new fathers at any given time. While there is a 5-year age span within our sample that may be associated with meaningful developmental change, our analyses will appropriately adjust for age of becoming a father. Additionally, we will conclude the study while all participants remain in their fourth decade of life prior to marked declines in sperm quality and fertility and increases in reproductive risks. ${ }^{71} 72^{9}$

Our decision to recruit both fathers and non-fathers will allow us, in longitudinal analyses, to examine differential effects for those transitioning and not transitioning to fatherhood. The inclusion of both fathers and nonfathers is a rare design strength, which contrasts to most studies investigating the transition to fatherhood in which men are recruited during a partner's pregnancy. ${ }^{24}{ }^{25} \mathrm{An}$ additional strength of MAPP is the multiple repeated measures, which will permit the use of various analytic approaches that investigate changes in patterns of interconnected factors over time (eg, cross-lagged path models, latent growth models and latent class transition models).

A risk to the longitudinal modelling is loss to follow-up. Longitudinal studies of men, and particularly those investigating matters related to family life and mental health risks, often report high levels of attrition. ${ }^{42}$ By the end of wave 3, MAPP had strong participation rates with $83 \%$ of men completing at least two waves, and the original cohort profile remained consistent following the low level of nonparticipation. Intensive cohort retention strategies that have continued into wave 4 data collection are resulting in men who missed prior waves returning to the study. For future analyses, this will result in a higher proportion of participants who have completed at least two annual surveys. As per our first two publications, ${ }^{69} 70$ to minimise sample biases that arise from loss to follow-up, we will manage missing data in future analyses using multiple imputation or other appropriate missing data handling techniques based on the pattern and amount of missingness. However, we acknowledge that there were 154 nonengaged eligible men who consented but did not go on to complete a survey and 56 men who participated in wave 1 but did not consent to further follow-up. Missing data techniques will not account for these participants.

A limitation of MAPP is that all data are self-report and, therefore, subject to associated biases. To augment this approach and explore biases, we periodically supplement our quantitative analyses with in-depth qualitative interviews. Two such studies have been published to date. The first reported on themes from interviews with nine MAPP participants without children related to their expectations of future fatherhood. ${ }^{73}$ The second qualitative study examined the experiences and decision-making processes of 11 MAPP participants who reported an absolute intention to remain childless in survey responses and yet whose plans were more equivocal when interviewed. ${ }^{36}$ The MAPP cohort includes participants from a diverse range of backgrounds and socioeconomic strata, with considerable demographic similarities to men of the same age. However, MAPP underrepresents men of the same age born outside of Australia and at baseline had higher rates of paid employment than the Australian population. This may limit generalisability of inferences drawn from the study.

As we noted when describing the cohort characteristics, a substantial proportion of MAPP participants report mental health symptomatology. However, it is unclear whether this represents slightly higher rates than men of a similar age in the Australian population or if MAPP has recruited previously hard-to-reach participants, possibly addressing non-response biases arising from underestimation of mental health symptoms in men noted in past studies. ${ }^{5863}$ Regardless, we suggest that rates in MAPP may be advantageous for the research questions that we aim 
to address. Our purpose is not to document community prevalence but rather to understand risk relationships. Adequate numbers of men with mental health vulnerabilities can allow for analyses of heterogeneity in changes to mental health risk over time.

\section{Significance}

The MAPP Study addresses a glaring under-representation of men and fathers in cohort studies that investigate the intersection of mental health and well-being with family life and roles at the normative age for becoming a father. The study will be well placed to inform policy and prevention opportunities and to guide psychosocial supports for men at this life stage. In Australia, this addresses a key priority of the National Men's Health Strategy 2020$2030^{20}$ and aligns with the national 'Case of Change' launched in Australia in 2020 that seeks to remove the barriers that limit fathers' engagement with health system supports and thereby promote healthier outcomes for all members of families. ${ }^{74}$

\section{Patient and public involvement}

We did not include public involvement in the development or design of the MAPP Study; however, we collaborate with multiple community fatherhood groups and health networks to maximise research dissemination. In particular, MAPP Study investigators are active members of the Australian Fatherhood Research Consortium, which disseminates research findings via social media, publishes the Australian Fatherhood Bulletin and hosts an annual symposium each year bringing together researchers, health service practitioners, father consumer groups, men's health advocates and policymakers.

\section{Data sharing}

Access to MAPP data is governed by the study investigators and can be initiated via contact with Dr Jacqui Macdonald (corresponding author). Data sharing must be consistent with ethical approvals for participant consent, confidentiality and data management. MAPP ethics approvals do not include participant consent for public availability of our data sets. However, we support requests for reuse of data for validation, verification or confirmation of previous research, subject to available resources at the time of the request to undertake sufficient deidentification of data for sharing.

\section{Collaboration}

Research proposals for new use of MAPP data (ie, first use of data for a research question $)^{75}$ will be subjected to approval from the study investigator group and take into account overlap with proposals or papers in preparation, suitability of the MAPP data to address the research question, capacity of the proposed authors to lead the paper and input required from the MAPP project team. MAPP investigators are particularly interested in cross-cohort replication studies. We, therefore, welcome collaboration with researchers with similar available data.

\section{Author affiliations}

${ }^{1}$ Centre for Social and Early Emotional Development, School of Psychology, Faculty of Health, Deakin University, Geelong, Victoria, Australia

${ }^{2}$ Centre for Adolescent Health, Murdoch Childrens Research Institute, Parkville, Victoria, Australia

${ }^{3}$ Department of Paediatrics, Faculty of Medicine, Dentistry and Health Sciences, University of Melbourne, Parkville, Victoria, Australia

${ }^{4}$ Health and Social Care Unit, School of Public Health and Preventive Medicine,

Monash University, Clayton, Victoria, Australia

${ }^{5}$ Warwick Business School, University of Warwick, Coventry, UK

${ }^{6}$ Department of Health Sciences and Biostatistics, Swinburne University of

Technology — Hawthorn Campus, Hawthorn, Victoria, Australia

${ }^{7}$ School of Health and Social Development, Deakin University Faculty of Health,

Burwood, Victoria, Australia

${ }^{8}$ Family Action Centre, The University of Newcastle, Callaghan, New South Wales, Australia

${ }^{9}$ Cairnmillar Institute, Camberwell, Victoria, Australia

${ }^{10}$ Parent-Infant Research Institute, Austin Health, Heidelberg, Victoria, Australia

${ }^{11}$ Melbourne School of Psychological Sciences, The University of Melbourne,

Melbourne, Victoria, Australia

Contributors JAM, HS, TK, CAO, JW, RJF and JM conceptualised the study design and research questions. JAM, LDM and LMF developed and managed study protocols, sampling procedures, cohort engagement and maintenance activities. CJG oversees all data science activities and is supported by JAM, GJY, LGG and LMF in data preparation and analyses. JAM, CLG and LMF prepared the protocol manuscript. All authors (JAM, LMF, CAO, HS, GJY, LGG, JW, RJF, TK, JM, LDM and CJG) provided feedback on drafts and endorsed the final manuscript.

Funding JAM is supported by a Deakin University, Faculty of Health, Mid-Career Fellowship. CAO is supported by an Australian National Health and Medical Research Council (NHMRC) Investigator Grant (APP1175086).

Competing interests None declared.

Patient and public involvement Patients and/or the public were not involved in the design, or conduct, or reporting, or dissemination plans of this research.

Patient consent for publication Not required.

Ethics approval Ethics approval for recruitment and MAPP Study data collection protocols was granted by Deakin University's Faculty of Health Human Ethics Advisory Group.

Provenance and peer review Not commissioned; externally peer reviewed.

Data availability statement Data are available upon reasonable request.

Open access This is an open access article distributed in accordance with the Creative Commons Attribution Non Commercial (CC BY-NC 4.0) license, which permits others to distribute, remix, adapt, build upon this work non-commercially, and license their derivative works on different terms, provided the original work is properly cited, appropriate credit is given, any changes made indicated, and the use is non-commercial. See: http://creativecommons.org/licenses/by-nc/4.0/.

\section{ORCID iDs}

Jacqui A Macdonald http://orcid.org/0000-0001-9451-2709

Lauren M Francis http://orcid.org/0000-0002-4050-5711

Helen Skouteris http://orcid.org/0000-0001-9959-5750

George J Youssef http://orcid.org/0000-0002-6178-4895

Liam G Graeme http://orcid.org/0000-0003-4497-2103

Joanne Williams http://orcid.org/0000-0002-5633-1592

Richard J Fletcher http://orcid.org/0000-0003-0970-4541

Tess Knight http://orcid.org/0000-0002-9231-9582

Jeannette Milgrom http://orcid.org/0000-0002-4082-4595

Laura Di Manno http://orcid.org/0000-0002-0769-7467

Craig A Olsson http://orcid.org/0000-0002-5927-2014

Christopher J Greenwood http://orcid.org/0000-0002-9211-6312

\section{REFERENCES}

1 Gentile S, Fusco ML. Untreated perinatal paternal depression: effects on offspring. Psychiatry Res 2017;252:325-32.

2 Glasser S, Lerner-Geva L. Focus on fathers: paternal depression in the perinatal period. Perspect Public Health 2019;139:195-8. 
3 Paulson JF, Bazemore SD, Goodman JH, et al. The course and interrelationship of maternal and paternal perinatal depression. Arch Womens Ment Health 2016;19:655-63.

4 Cameron EE, Sedov ID, Tomfohr-Madsen LM. Prevalence of paternal depression in pregnancy and the postpartum: an updated meta-analysis. J Affect Disord 2016;206:189-203.

5 Giallo R, D'Esposito F, Christensen D, et al. Father mental health during the early parenting period: results of an Australian population based longitudinal study. Soc Psychiatry Psychiatr Epidemiol 2012;47:1907-16.

6 Wee KY, Skouteris H, Richardson B, et al. The inter-relationship between depressive, anxiety and stress symptoms in fathers during the antenatal period. J Reprod Infant Psychol 2015;33:359-73.

7 Leach LS, Poyser C, Cooklin AR, et al. Prevalence and course of anxiety disorders (and symptom levels) in men across the perinatal period: a systematic review. J Affect Disord 2016;190:675-86.

8 Philpott LF, Leahy-Warren P, FitzGerald S, et al. Stress in fathers in the perinatal period: a systematic review. Midwifery 2017;55:113-27.

9 Ramchandani P, Stein A, Evans J, et al. Paternal depression in the postnatal period and child development: a prospective population study. Lancet 2005;365:2201-5.

10 Ramchandani PG, Stein A, O'Connor TG, et al. Depression in men in the postnatal period and later child psychopathology: a population cohort study. J Am Acad Child Adolesc Psychiatry 2008; $47: 390-8$

11 Shapiro AF, Gottman JM, Carrère $S$. The baby and the marriage: identifying factors that buffer against decline in marital satisfaction after the first baby arrives. J Fam Psychol 2000;14:59-70.

12 Claxton A, Perry-Jenkins M. No fun anymore: leisure and marital quality across the transition to parenthood. $J$ Marriage Fam 2008;70:28-43.

13 Amodia-Bidakowska A, Laverty C, Ramchandani PG. Father-child play: A systematic review of its frequency, characteristics and potential impact on children's development. Developmental Review 2020;57:100924.

14 Sarkadi A, Kristiansson R, Oberklaid F, et al. Fathers' involvement and children's developmental outcomes: a systematic review of longitudinal studies. Acta Paediatr 2008;97:153-8.

15 Webster L, Low J, Siller C, et al. Understanding the Contribution of a Father's Warmth on His Child's Social Skills. Fathering 2013;11:90-113.

16 CDC. Preconception health and health care: information for men: centers for disease control and prevention, 2020. Available: https:// www.cdc.gov/preconception/men.htm

17 Frey KA, Navarro SM, Kotelchuck M, et al. The clinical content of preconception care: preconception care for men. Am J Obstet Gynecol 2008;199:S389-95.

18 Fletcher RJ, May C, StGeorge JS. Engaging fathers: evidence review. Canberra: Australian Research Alliance for Children and Youth (ARACY), 2014.

19 Panter-Brick C, Burgess A, Eggerman M, et al. Practitioner review: Engaging fathers--recommendations for a game change in parenting interventions based on a systematic review of the global evidence. J Child Psychol Psychiatry 2014;55:1187-212.

20 Australian Government. National Men's Health Strategy 2020-2030. Canberra: Commonwealth of Australia, 2019.

21 Wee KY, Pier C, Milgrom J, et al. Fathers' mental health during the ante-and postnatal periods: Knowledge, recommendations and interventions. Br J Midwifery 2013;21:342-53.

22 Australian Bureau of Statistics. 3303.0 - Causes of Death, Australia, 2018. Canberra, 2019.

23 Hee Ahn M, Park S, Ha K, et al. Gender ratio comparisons of the suicide rates and methods in Korea, Japan, Australia, and the United States. J Affect Disord 2012;142:161-5.

24 Condon JT, Boyce P, Corkindale CJ. The first-time fathers study: a prospective study of the mental health and wellbeing of men during the transition to parenthood. Aust N Z J Psychiatry 2004;38:56-64.

25 Molgora S, Fenaroli V, Malgaroli M, et al. Trajectories of postpartum depression in Italian first-time fathers. Am J Mens Health 2017;11:880-7.

26 Northstone K, Lewcock M, Groom A, et al. The Avon longitudinal study of parents and children (ALSPAC): an update on the enrolled sample of index children in 2019. Wellcome Open Res 2019;4:51.

27 Pirkis J, Macdonald J, English DR. Introducing ten to men, the Australian longitudinal study on male health. BMC Public Health 2016;16:1044.

28 Condon J, Corkindale C, Boyce P, et al. A longitudinal study of father-to-infant attachment: antecedents and correlates. J Reprod Infant Psychol 2013;31:15-30.
29 Goldman R, Burgess A. Where's the daddy? Fathers and fatherfigures in UK datasets (Executive Summary). Marlborough, 2017.

30 Davison KK, Gicevic S, Aftosmes-Tobio A, et al. Fathers' representation in observational studies on parenting and childhood obesity: a systematic review and content analysis. Am J Public Health 2016;106:e14-21.

31 Fahey JO, Shenassa E. Understanding and meeting the needs of women in the postpartum period: the perinatal maternal health promotion model. J Midwifery Womens Health 2013;58:613-21.

32 Eggebeen DJ, Knoester C, McDaniel B. The implications of fatherhood for men. In: Cabrera NJ, Tamis-LeMonda CS, eds. Handbook of father involvement: multidisciplinary perspectives. 2nd ed. New York: Taylor and Francis, 2013.

33 Buist A, Morse CA, Durkin S. Men's Adjustment to Fatherhood: Implications for Obstetric Health Care. Journal of Obstetric, Gynecologic \& Neonatal Nursing 2003;32:172-80.

34 Boyce P, Condon J, Barton J, et al. First-Time fathers' study: psychological distress in expectant fathers during pregnancy. Aust N Z J Psychiatry 2007;41:718-25.

35 Einiö E, Goisis A, Myrskylä M. Is the relationship between men's age at first birth and midlife health changing? Evidence from two British cohorts. SSM Popul Health 2019;8:100458.

36 Smith I, Knight T, Fletcher R, et al. When men choose to be childless: an interpretative phenomenological analysis. J Soc Pers Relat 2020;37:325-44.

37 Fisher J, Hammarberg K. Psychological Aspects of Infertility Among Men. In: Simoni M, Huhtaniemi I, eds. Endocrinology of the testis and male reproduction. Springer, Cham, 2017.

38 Nylund-Gibson K, Choi AY. Ten frequently asked questions about latent class analysis. Trans/ Issues Psychol Sci 2018;4:440-61.

39 Australian Bureau of Statistics. 3301.0 - births, Australia, 2016, 2016.

40 Loxton D, Powers J, Anderson AE, et al. Online and Offline recruitment of young women for a longitudinal health survey: findings from the Australian longitudinal study on women's health 1989-95 cohort. J Med Internet Res 2015;17:e109.

41 Harris PA, Taylor R, Thielke R, et al. Research electronic data capture (REDCap)--a metadata-driven methodology and workflow process for providing translational research informatics support. $J$ Biomed Inform 2009;42:377-81.

42 Teague S, Youssef GJ, Macdonald JA, et al. Retention strategies in longitudinal cohort studies: a systematic review and meta-analysis. BMC Med Res Methodol 2018;18:151.

43 Muthen LK, Muthen B O. Mplus: Statistical Analysis with Latent Variables: User's Guide (Version 8). Los Angeles, CA: Authors, 2017

44 Kyriazos TA. Applied Psychometrics: sample size and sample power considerations in factor analysis (EFA, CFA) and SEM in general. Psychology 2018;09:2207-30.

45 Wilson Van Voorhis CR, Morgan BL. Understanding power and rules of thumb for determining sample sizes. Tutor Quant Methods Psychol 2007;3:43-50.

46 Australian Bureau of Statistics. Socio-Economic indexes for areas for Australia (SEIFA), 2016 (cat. No. 2033.0.55.001). Canberra, Australia, 2018.

47 Australian Bureau of Statistics. 6227.0 - Education and Work, Australia, May 2019. Canberra, Australia, 2019.

48 Australian Bureau of Statistics. 412250DS0001 gender indicators, Australia, November 2019. Canberra, Australia, 2019.

49 Australian Bureau of Statistics. 2071.0 Census of Population and Housing: Reflecting Australia - Stories from the Census - Cultural Diversity. Canberra, Australia, 2017.

50 Australian Bureau of Statistics. 2071.0 Census of Population and Housing: Reflecting Australia - Storries from the Census 2016 Aboriginal and Torres Strait Islander Population. Canberra, Australia, 2017.

51 Australian Bureau of Statistics. 4159.0 - General Social Survey: Summary Results, Australia, 2014. Canberra, Australia, 2015.

52 Australian Institute of Family Studies. Ten to men: the Australian longitudinal study on male health, 2019. Available: https://tentomen. org.au

53 Lovibond SH, Lovibond PF. Manual for the depression anxiety stress scales. 2nd ed. Sydney: Psychology Foundation, 1995.

54 Antony MM, Bieling PJ, Cox BJ, et al. Psychometric properties of the 42 -item and 21 -item versions of the depression anxiety stress scales in clinical groups and a community sample. Psychol Assess 1998;10:176-81.

55 Crawford J, Cayley C, Lovibond PF, et al. Percentile norms and accompanying interval estimates from an Australian general adult population sample for Self-Report mood scales (BAI, BDI, CRSD, CES-D, DASS, DASS-21, STAI-X, STAI-Y, SRDS, and SRAS). Aust Psychol 2011;46:3-14. 
56 Australian Bureau of Statistics. National survey of mental health and wellbeing: summary of results, Australia, 2007. ABS cat. No. 4326.0. Canberra, 2008

57 Kessler RC, Ustün TB. The world mental health (WMH) survey initiative version of the world Health organization (who) composite international diagnostic interview (CIDI). Int J Methods Psychiatr Res 2004;13:93-121.

58 Australian Bureau of Statistics. National survey of mental health and wellbeing: summary of results, methodology. Canberra, Australia, 2008.

59 Kroenke K, Spitzer RL, Williams JB. The PHQ-9: validity of a brief depression severity measure. J Gen Intern Med 2001;16:606-13.

60 Terhaag S, Quinn B, Swami N. Mental health of Australian males: depression, suicidality and loneliness. In: Daraganova G, Quinn B, eds. Insights \#1: Findings from Ten to Men: The Australian Longitudinal Study on Male Health. Melbourne: Australian Institute of Family Studies, 2020: 2013-6.

61 Bandara D, Howell L, Silbert M. Ten to men: the Australian longitudinal study on male health - data user guide, version 3.0. Melbourne: Australian Institute of Family Studies, 2019.

62 Psouni E, Agebjörn J, Linder H. Symptoms of depression in Swedish fathers in the postnatal period and development of a screening tool. Scand J Psychol 2017;58:485-96.

63 Batterham PJ. Recruitment of mental health survey participants using Internet advertising: content, characteristics and cost effectiveness. Int J Methods Psychiatr Res 2014;23:184-91.

64 Fonagy P, Luyten P, Moulton-Perkins A, et al. Development and validation of a self-report measure of Mentalizing: the reflective functioning questionnaire. PLoS One 2016;11:e0158678.

65 Luyten P, Mayes LC, Nijssens L, et al. The parental reflective functioning questionnaire: development and preliminary validation. PLoS One 2017;12:e0176218.

66 Condon JT, Corkindale CJ, Boyce P. Assessment of postnatal paternal-infant attachment: development of a questionnaire instrument. J Reprod Infant Psychol 2008;26:195-210.

67 Duckett S, Stobart A. Australia's COVID-19 response: the story so far Melbourne. Australia: Grattan Institute, 2020. https://grattan.edu. au/news/australias-covid-19-response-the-story-so-far/

68 Victorian Government Department of Health and Human Services. Media hub - coronavirus (COVID-19) Melbourne, Australia, 2020. Available: https://www.dhhs.vic.gov.au/media-hub-coronavirusdisease-covid-19 [Accessed 6 Nov 2020].

69 Macdonald JA, Greenwood CJ, Francis LM, et al. Profiles of depressive symptoms and anger in men: associations with postpartum family functioning. Front Psychiatry 2020;11:578114.

70 Macdonald JA, Graeme LG, Wynter K, et al. How are you sleeping? starting the conversation with fathers about their mental health in the early parenting years. J Affect Disord 2021;281:727-37.

71 Bray I, Gunnell D, Davey Smith G. Advanced paternal age: how old is too old? J Epidemiol Community Health 2006;60:851-3.

72 Brandt JS, Cruz Ithier MA, Rosen T, et al. Advanced paternal age, infertility, and reproductive risks: a review of the literature. Prenat Diagn 2019;39:81-7.

73 Kings CA, Knight T, Ryan D, et al. The "sensory deprivation tank": An interpretative phenomenological analysis of men's expectations of first-time fatherhood. Psychol Men Masc 2017;18:112-22.

74 Male H. Plus paternal: focus on fathers. Melbourne, Australia, 2020.

75 Pasquetto IV, Randles BM, Borgman CL. On the reuse of scientific data. Data Sci J 2017;16:8.

76 Australian Institute of Family Studies. Growing up in Australia: the longitudinal study of Australian children, 2018.

77 Holtzman S, O'Connor BP, Barata PC, et al. The brief irritability test (bite): a measure of irritability for use among men and women. Assessment 2015;22:101-15.

78 Spielberger CD. State-Trait Anger Expression Inventory-2. In: Freeman SJ, Klecker BM, eds. STAXI-2, 1999.

79 Orth U, Berking M, Burkhardt S. Self-conscious emotions and depression: rumination explains why shame but not guilt is maladaptive. Pers Soc Psychol Bull 2006;32:1608-19.
80 Ryff CD, Keyes CL. The structure of psychological well-being revisited. J Pers Soc Psychol 1995;69:719-27.

81 Carver CS. You want to measure coping but your protocol's too long: consider the brief cope. Int J Behav Med 1997;4:92-100.

82 Lun J, Kesebir S, Oishi S. On feeling understood and feeling well: the role of interdependence. J Res Pers 2008;42:1623-8.

83 Rice SM, Fallon BJ, Aucote HM, et al. Development and preliminary validation of the male depression risk scale: furthering the assessment of depression in men. J Affect Disord 2013;151:950-8.

84 Haskett ME, Ahern LS, Ward CS, et al. Factor structure and validity of the parenting stress index-short form. J Clin Child Adolesc Psychol 2006;35:302-12.

85 Fujiwara T, Okuyama M, Takahashi K. Paternal involvement in childcare and unintentional injury of young children: a populationbased cohort study in Japan. Int J Epidemiol 2010;39:588-97.

86 Feinberg ME, Brown LD, Kan ML. A multi-domain self-report measure of Coparenting. Parent Sci Pract 2012;12:1-21.

87 Rholes WS, Simpson JA, Blakely BS, et al. Adult attachment styles, the desire to have children, and working models of parenthood. $J$ Pers 1997;65:357-85.

88 Parker G, Tupling H, Brown LB. A parental bonding instrument. Br J Med Psychol 1979;52:1-10.

89 Zimet GD, Dahlem NW, Zimet SG, et al. The multidimensional scale of perceived social support. J Pers Assess 1988;52:30-41.

90 Braiker HB, Kelley HH. 5 - Conflict in the Development of Close Relationships11The preparation of this paper and the original research reported in it were made possible by a grant from the National Science Foundation (GS-33069X) to Kelley. In: Burgess $\mathrm{RL}$, Huston TL, eds. Social exchange in developing relationships: academic press, 1979: 135-68.

91 Spanier GB, Thompson L. A confirmatory analysis of the Dyadic adjustment scale. J Marriage Fam 1982;44:731-8.

92 Rizzo JR, House RJ, Lirtzman SI. Role conflict and ambiguity in complex organizations. Adm Sci Q 1970;15:150-63.

93 Lobel SA, Clair LS. Effects of family responsibilities, gender, and career identity salience on performance outcomes. Acad Manage $J$ 1992;35:1057-69.

94 Mahalik JR, Locke BD, Ludlow LH, et al. Development of the conformity to masculine norms inventory. Psychol Men Masc 2003;4:3-25.

95 Deci EL, Ryan RM, Gagné M, et al. Need satisfaction, motivation, and well-being in the work organizations of a former eastern bloc country: a cross-cultural study of Self-Determination. Personality and Social Psychology Bulletin 2001;27:930-42.

96 Leach L, Butterworth P, Rodgers B. Deriving an evidence-based measure of job quality from the HILDA survey. Australian Social Policy Journal 2010;9:67-86.

97 Donnelly EA, Chonody J, Campbell D. Measuring chronic stress in the emergency medical services. $J$ Workplace Behav Health 2014;29:333-53.

98 Sibley CG, Luyten N, Purnomo M. The Mini-IPIP6: validation and extension of a short measure of the Big-Six factors of personality in New Zealand. New Zealand Journal of Psychology 2011;40:142-59.

99 Cox BJ, Enns MW, Clara IP. The multidimensional structure of perfectionism in clinically distressed and college student samples. Psychol Assess 2002;14:365-73.

100 Bowling $A$. Just one question: if one question works, why ask several? J Epidemiol Community Health 2005;59:342-5.

101 Buysse DJ, Reynolds CF, Monk TH, et al. The Pittsburgh sleep quality index: a new instrument for psychiatric practice and research. Psychiatry Res 1989;28:193-213.

102 Coddington RD. The significance of life events as etiologic factors in the diseases of children. II. A study of a normal population. $J$ Psychosom Res 1972;16:205-13.

103 Saunders JB, Aasland OG, Babor TF, et al. Development of the Alcohol Use Disorders Identification Test (AUDIT): WHO Collaborative Project on Early Detection of Persons with Harmful Alcohol Consumption--II. Addiction 1993;88:791-804. 


\section{University Library}

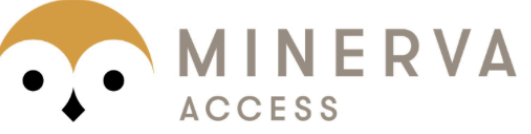

A gateway to Melbourne's research publications

Minerva Access is the Institutional Repository of The University of Melbourne

Author/s:

Macdonald, JA;Francis, LM;Skouteris, H;Youssef, GJ;Graeme, LG;Williams, J;Fletcher, RJ;Knight, T;Milgrom, J;Di Manno, L;Olsson, CA;Greenwood, CJ

Title:

Cohort profile: the Men and Parenting Pathways (MAPP) Study: a longitudinal Australian cohort study of men's mental health and well-being at the normative age for first-time fatherhood

Date:

2021-01-01

Citation:

Macdonald, J. A., Francis, L. M., Skouteris, H., Youssef, G. J., Graeme, L. G., Williams, J., Fletcher, R. J., Knight, T., Milgrom, J., Di Manno, L., Olsson, C. A. \& Greenwood, C. J. (2021). Cohort profile: the Men and Parenting Pathways (MAPP) Study: a longitudinal Australian cohort study of men's mental health and well-being at the normative age for firsttime fatherhood. BMJ OPEN, 11 (7), https://doi.org/10.1136/bmjopen-2020-047909.

Persistent Link:

http://hdl.handle.net/11343/287550

License:

CC BY-NC 